\title{
RADIOLOGICAL FINDINGS OF PULMONARY TUBERCULOSIS IN PATIENTS WITH AND WITHOUT HIV INFECTIONS
}

Radhiana binti Hassan ${ }^{1}$, Haziq Hussaini bin Fauzi ${ }^{2}$, Kamil Irsyad bin Yusoff ${ }^{2}$, Muhammad Faizol bin Mohd Satar ${ }^{2}$ and Hafizah bt Pasi ${ }^{3}$

${ }^{1}$ Department of Radiology, Kulliyyah of Medicine, IIUM, Pahang, Malaysia, ${ }^{2}$ MBBS, Kulliyyah of Medicine, IIUM, Pahang, Malaysia, ${ }^{3}$ Department of Community Medicine, Kulliyyah of Medicine, IIUM, Pahang, Malaysia.

Presenter: Radhiana binti Hassan, radhianahassan@iium.edu.my

Introduction: Radiological manifestation of pulmonary tuberculosis in HIV positive patients is different with HIV negative patients. We aim to determine the differences in chest radiological findings of Pulmonary Tuberculosis among HIV and non-HIV infected patients in HTAA.

Materials and method: A retrospective study was conducted in Chest Clinic, Hospital Tunku Ampuan Afzan, Kuantan Pahang. There were 101 chest radiographs with sputum smear-positive retrieved and reviewed. Socio-demographic status and chest radiographs findings were documented and analyzed.

Results: Of the 101 patients, 12 patients were HIV positive. Of the 89 HIV negative patients, $96 \%$ had consolidation change on chest radiograph, in contrast with HIV positive patients, only $4 \%$ among them had this appearance and this is statistically significant ( $p$ value less than 0.05$)$. Mediastinal lymphadenopathy is significantly higher (17\%) in HIV positive patients compared to HIV negative patients (1\%). Normal chest radiographs were more common in HIV positive patients (33\%) as compared to HIV negative patients (2\%).

Conclusion: HIV positive patients with pulmonary tuberculosis exhibit different radiological manifestation on chest radiograph when compared to HIV negative patients. 